\title{
Implementation Of Augmented Reality Procedures For Prayer Using Marker- Based Tracking Method
}

\section{Implementasi Augmented Reality Tata Cara Sholat Menggunakan Metode Marker-Based Tracking}

\author{
Adi Darmanto ${ }^{1}$, Faisal Reza Pradhana ${ }^{2}$, Lukman Effendi ${ }^{3}$, Dihin Muriyatmoko ${ }^{4}$, Oddy \\ Virgantara Putra ${ }^{5}$ \\ \{adidarmanto@mhs.unida.gontor.ac.id, faisalrezapradhana@mhs.unida.gontor.ac.id, lukman@unida.gontor.ac.id, \\ dihinmuriyatmoko@unida.gontor.ac.id,oddy@unida.gontor.ac.id \}
}

Program Studi Teknik Informatika, Fakultas Sains dan Teknologi, Universitas Darussalam Gontor

\begin{abstract}
Abstact. Prayer learning activities at PAS Baitul Qur'an Ponorogo Kindergarten have so far been carried out with face-toface practice between teachers and students. However, the teachers teach the proper way of praying during the pandemic. This study aims to introduce Augmented Reality (AR) technology to teachers and children as a medium for learning to pray. From this research resulted in the application "Let's Learn Prayer" which contains guidance on how to pray and pray in the form of three-dimensional animation. In addition, this application is equipped with a card (marker) that represents each prayer movement. The animation of the prayer can move when the user does the marking. As a result, animations can appear on the smartphone screen. This application development stage uses Waterfall model steps and marker-based tracking. The use of AR applications for prayer learning can increase students' interest and understanding in implementing prayer movements.
\end{abstract}

Keywords - animation, application, augmented reality, prayer, 3D, ayo belajar sholat

\begin{abstract}
Abstrak. Kegiatan pembelajaran salat di TK PAS Baitul Qur'an Ponorogo selama ini dilakukan dengan praktik tatap muka langsung antara guru dan murid. Namun para guru kesulitan mengajarkan tata cara salat yang benar di masa pandemi. Penelitian ini bertujuan untuk mengenalkan teknologi Augmented Reality (AR) kepada para guru dan anak-anak sebagai media pembelajaran salat. Dari penelitian tersebut menghasilkan aplikasi "Ayo Belajar Sholat" yang berisikan tuntunan tata cara salat dan doa dalam bentuk animasi tiga dimensi. Selain itu, aplikasi ini dilengkapi dengan kartu (marker) yang merepresentasikan setiap gerakan salat. Animasi dari salat bisa bergerak ketika pengguna memindai marker yang dikehendaki. Hasilnya, animasi bisa muncul di layar smartphone. Tahapan pengembangan aplikasi ini menggunakan langkah-langkah model Waterfall dan marker-based tracking. Penggunaan aplikasi AR pembelajaran salat dapat meningkatkan minat dan pemahaman siswa dalam mengimplementasikan gerakan salat.
\end{abstract}

Kata Kunci - animasi, aplikasi, augmented reality, sholat, 3D, ayo belajar sholat

\section{Pendahuluan}

Media pembelajaran yang menggunakan teknologi modern sekarang mulai banyak di pakai oleh tenaga Pendidikan, di karnakan teknologi mempermudah dan mempercepat suatu pekerjaan yang ada dalam keseharian hidup kita. Teknologi yang biasa digunakan di Taman kanak-kanak sebagai media pembelajaran biasanya berupa teknologi musik yang mempermudah siswa dalam menyerap pelajaran. Anak usia taman kanak-kanak biasanya menyukai pembelajaran secara visualisasi, karena anak-anak tersebut menyukai hal yang menarik seperti, animasi, gambar dan visualisasi yang lainnya. Anak-anak kurang bisa menangkap pelajaran yang disampaikan oleh gurunya, guru biasanya menerangkan suatu hal kepada muridnya hanya sebatas menerangkan tanpa memperdulikan hal yang disampaikan tersebut menarik atau tidak. Hal ini mengakibatkan sebagian anak-anak kurang memperhatikan apa yang disampaikan oleh gurunya, sehingga pelajaran kurang terserap secara optimal[1].

Augmented reality $(A R)$ adalah kombinasi objek nyata dan virtual dalam lingkungan nyata, operasi interaktif waktu nyata, dan integrasi waktu nyata antar objek.Tiga dimensi, yaitu objek virtual yang terintegrasi dengan dunia nyata. Penggunaan teknologi tampilan yang tepat dapat menggabungkan objek nyata dan virtual, dapat berinteraksi melalui perangkat input tertentu, dan integrasi yang baik memerlukan pelacakan yang efektif. Dengan memanfaatkan teknologi AR akan menambah daya tarik serta dapat merangsang daya ingin tahu anak untuk belajar. Visualisasi AR yang berupa animasi 3D pastinya membuat anak-anak lebih berantusias dari pada hanya mendengarkan pelajaran dari gurunya[2].

Berdasarkan survey yang telah di lakukan, di TK PAS Baitul Qur'an Ponorogo yang pembelajarannya masih menggunakan media manual berbasis buku dan papan tulis. Pembelajaran manual tersebut kurang efektif di masa pandemi, karna tidak adanya pembelajaran tatap muka[3]. 
Penelitian ini bertujuan untuk mengenalkan teknologi AR kepada anak-anak TK PAS Baitul Qur'an sebagai media pembelajaran. Dari penelitian tersebut menghasilkan Aplikasi "Ayo Belajar Sholat". Aplikasi tersebut berisikan tuntunan tata cara salat dan doanya berbentuk objek 3D yang juga diberi animasi agar terkesan realistis dan interaktif serta objek akan muncul di atas kartu (marker) yang telah di sediakan. Aplikasi ini bisa di gunakan menggunakan smartphone atau tablet yang perangkatnya mempunyai operating system android. Media.ini bergantung pada android dan dibuat menggunakan perangkat seperti Blender 3D, Corel Draw dan Unity 3D. Aplikasi ini dapat berjalan di ponsel berukuran tidak kurang dari 200 MB dan kamera belakang 13 MP. Media ini berbasis android yang dibuat dengan menggunakan model Waterfall dengan menggunakan teknik marker based tracking. Penggunaan aplikasi AR pembelajaran sholat dapat meningkatkan minat belajar siswa serta tingkat pemahaman siswa terhadap materi salat yang ditunjukan dengan peningkatan nilai sebelum dan sesudah menggunakan aplikasi[4].

Dalam sebuah tinjauan yang diidentikkan dengan pembelajaran bahasa Arab berbasis augmented reality yang diperluas, diungkapkan bahwa inovasi AR memiliki opsi untuk meningkatkan media pembelajaran bahasa Arab di Unida Gontor dan dapat bermanfaat bagi peningkatan pembelajaran dilingkungan dan pesantren maupun masyarakat. Untuk situasi ini, isi yang ditampilkan dalam aplikasi AR adalah melalui hal-hal yang digambarkan dalam artikel 3 dimensi[5].

Penelitian berikutnya membahas tentang augmented reality sebagai media pembelajaran Shalat dan penelitian ini memakai Metode FAST (Feture Form Accelerated segment Test). Aplikasi ini tujuannya untuk membantu siswa sekolah dasar yang baru belajar gerakan shalat agar anak-anak semakin antusias dan tertarik dalam mempelajari gerakan shalat[6]. Selanjutnya sebuah penelitian membahas tentang pembelajaran wudhu untuk TPQ An-Nur yang menggunakan Metode User Acceptence Test (UAT). Penelitian Pengembangan Animasi 3D Media Pembelajaran wudhu dan tayamum Berbasis Android ini menggunakan metode Multimedia Development Life Cycle (MDLC). Peningkatan hasil belajar menggunakan aplikasi tersebut sebesar 0,4 dengan kriteria sedang dan UAT dengan rata sebesar $87 \%$ [7].

Tujuan dari penelitian ini untuk mengatasi kendala kegiatan belajar mengajar di masa pandemi dengan cara mengenalkan teknologi AR tentang gerakan salat kepada anak TK. Penelitian tersebut menggunakan metode Marker Based Tracking yang penerapannya menggunakan kartu marker sehingga menambah minat anak untuk belajar[8].

\section{METODE}

Metode perancangan perangkat lunak dalam penelitian ini menggunakan Software Development Life Cycle dengan model waterfall. waterfall adalah model pengembangan perangkat lunak di mana alur proses secara bertahap mengalir ke bawah. Dengan menggunakan model pengembangan waterfall, pengembang melakukan enam tahap pengembangan software, yaitu: requirements, design, implementation, testing, maintenance. Tahapan pengembangan aplikasi pada penelitian ini disajikan pada [9].

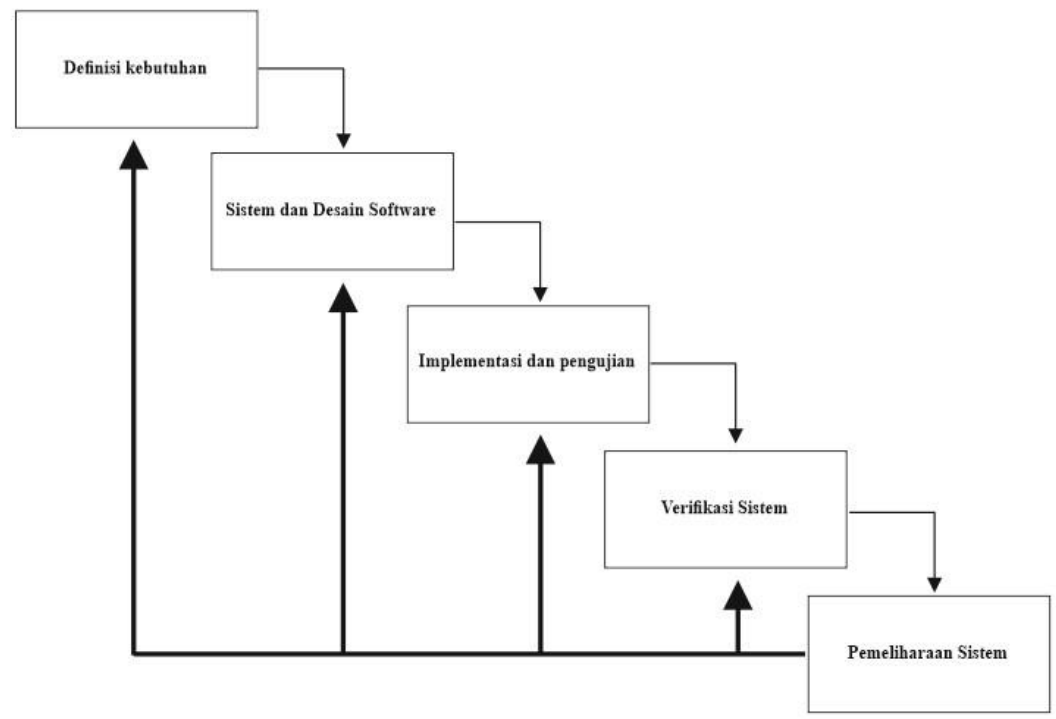

Gambar 1 Tahap Penelitian Aplikasi Ayo Belajar Sholat[10]

Tahap-tahap metode waterfall dalam setiap tahapan dapat dijelaskan sebagai berikut : 
a. Analisa Kebutuhan

Dalam kasus pembuatan aplikasi augmented reality pada media pembelajaran tuntunan praktik salat "Ayo Belajar Sholat" dilakukan dengan mengamati proses pembelajaran salat serta melakukan wawancara dengan salah satu guru yang bertanggung jawab pada TK PAS Baitul Qur' an. Kesimpulan yang dapat di ambil dari survey yang telah di lakukan adalah pembelajaran praktik salat secara manual di masa pandemi mempunyai kendala dalam penerapannya.

b. Desain Sistem

Pada tahap ini, pelaksanaan dan rencana kerangka dari permasalahan yang ada dilengkapi dengan bantuan perangkat system seperti diagram alir data, diagram hubungan entitas dan struktur data. Saat membuat aplikasi "Ayo Belajar Sholat" ini, kami menggunakan use case diagram, activity diagram, class diagram, dan sequence diagram.

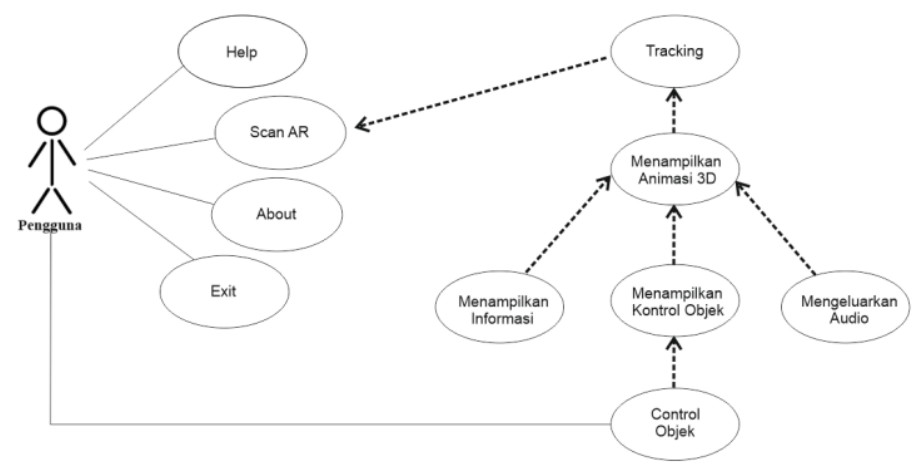

Gambar 2 Use Case Diagram Aplikasi Ayo Belajar Sholat

Pada gambar 2 Use case diagram, menggambarkan apa yang dilakukan pengguna. Mulai dari memilih menu AR Scan, Help, About, dan Exit. Pengguna memasuki aplikasi dan sistem mengenali marker/kartu. Setelah memilih menu scan AR sistem akan mengenali marker yang dideteksi oleh sistem maka akan terjadi render objek. Menu hekp memberikan petunjuk tentang cara menggunakan aplikasi AR. Sedangkan menu about informasi tentang pengembang aplikasi ditampilkan pada menu informasi aplikasi AR. Menu exit digunakan ketika pengguna ingin keluar dari aplikasi.

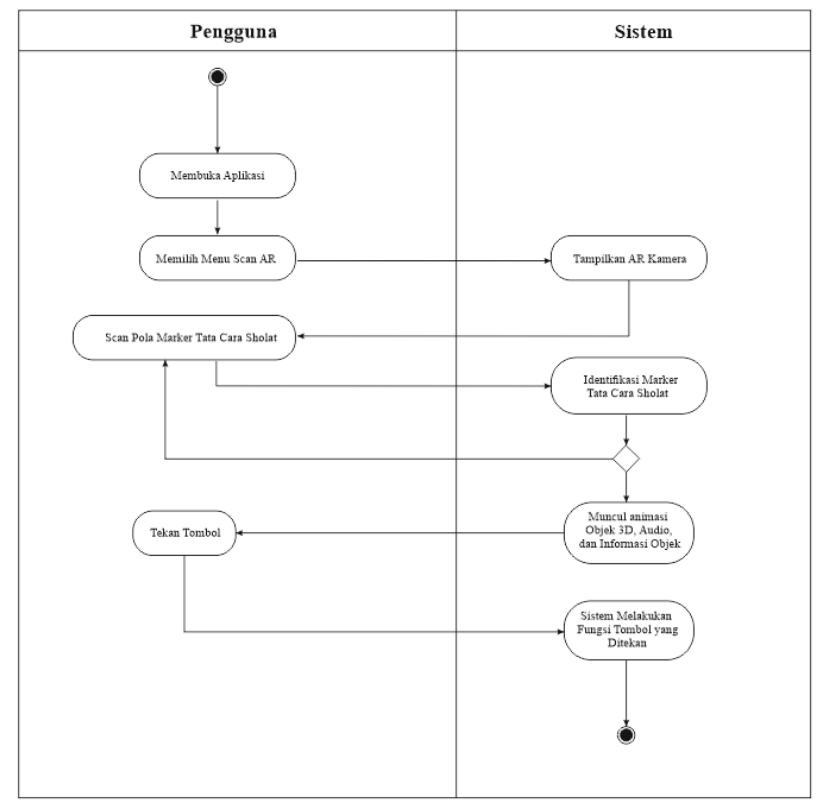

Gambar 3 Activity Diagram Aplikasi Ayo Belajar Sholat

Pada gambar 3 Activity Diagram yang merupakan representasi grafik dari alur yang melibatkan aktifitas dan aksi secara bertahap pada aplikasi Tata cara Sholat AR, sehingga pembuatan halaman atau activity 
Procedia of Engineering and Life Science Vol. 1. No. 2 Juni 2021

Seminar Nasional \& Call Paper Fakultas Sains dan Teknologi (SENASAINS 2nd)

Universitas Muhammadiyah Sidoarjo

menjadi lebih mudah. Tracking Marker menjelaskan alur kerja actor yang menjalankan aplikasi AR untuk melacak marker yang disorot oleh kamera $A R$.

c. Penulisan Kode Program

Pada penulisan kode program atau coding adalah proses untuk mewujudkan metode yang sudah dibuat supaya metode marker based tracking itu dapat berjalan dengan baik. Code ini dibuat dengan unity 2018, visual code 2017. Tahapan code program ini digunakan untuk menghasilkan User Interface.

d. Pengujian Program

Tahap pengujian program dilakukan pada saat sistem dibuat, agar mengetahui kinerja sistem yang telah di buat. Tahapan ini diuji dengan black box dengan cara memasangkan apk ke tiga perangkat smartphone yang berbeda dan di ujikan dengan cara menguji satu persatu setiap tombol apakah bisa berjalan dengan baik.

\section{Hasil dan Pembahasan}

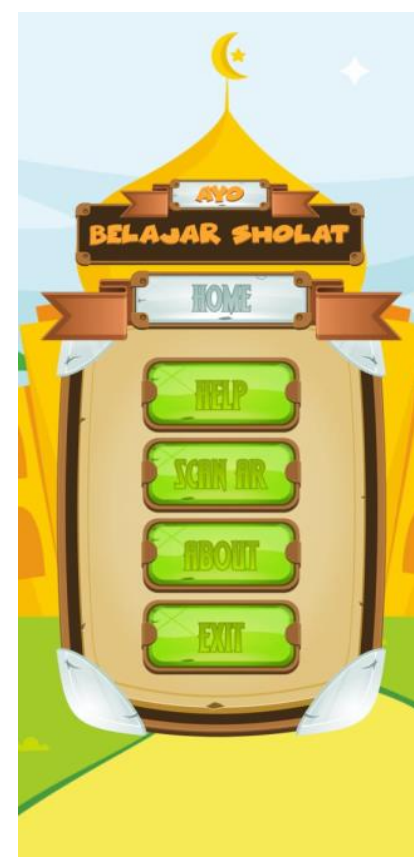

(a)

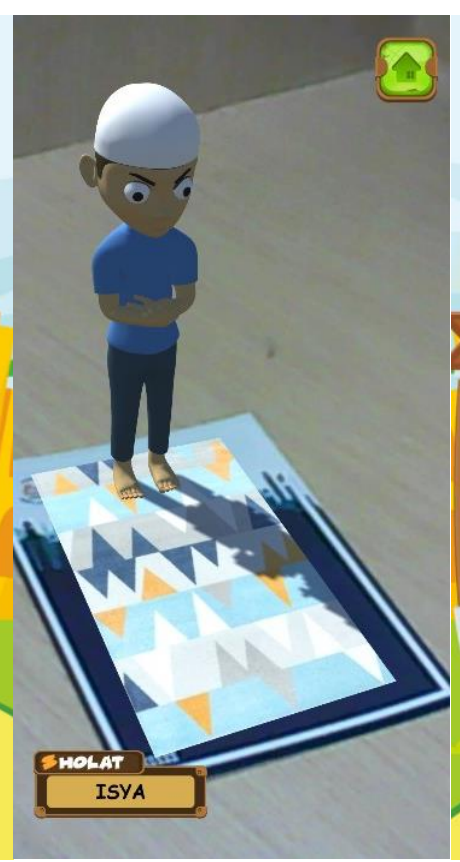

(b)

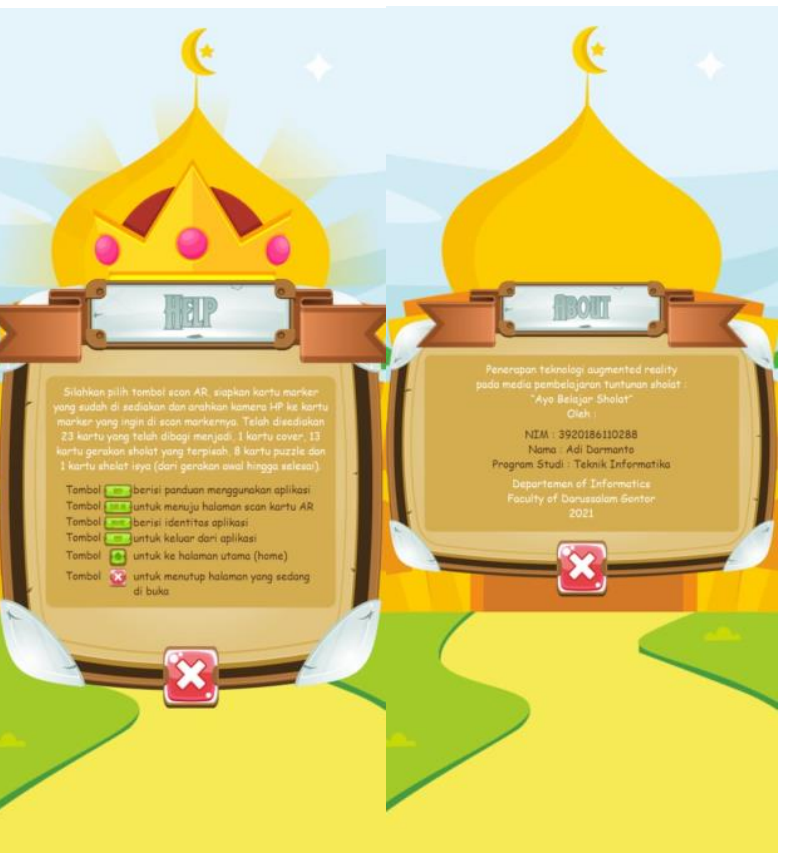

(c) (d)

Gambar 4 User Interface Ayo Belajar Sholat

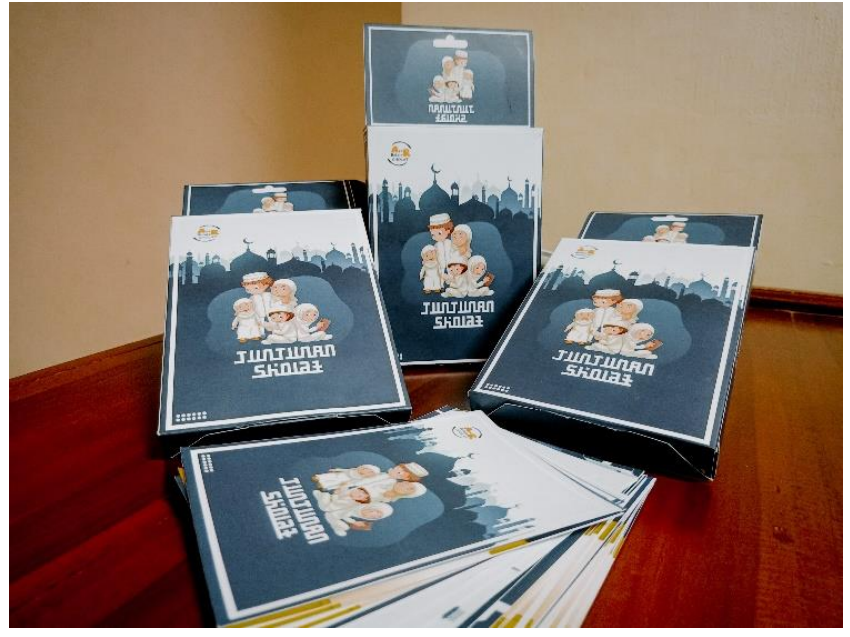

Gambar 5 marker/kartu 
Procedia of Engineering and Life Science Vol. 1. No. 2 Juni 2021

Seminar Nasional \& Call Paper Fakultas Sains dan Teknologi (SENASAINS 2nd)

Universitas Muhammadiyah Sidoarjo

Dari penelitian ini di hasilkan aplikasi "Ayo Belajar Sholat" yang menggunakan teknologi augmented reality berbasis android. Fitur-fitur dari aplikasi tersebut sebagai berikut :

1. Antarmuka Tampilan Halaman Menu Utama

Pada gambar 4(a), halaman menu utama aplikasi terdapat empat pilihan menu aplikasi yang digunakan, yaitu Help, Scan AR, About dan Exit.

2. Antarmuka Tampilan Halaman Start Scan

Pada gambar 4(b), di halaman ini user mencari penanda (marker/kartu) sampai di temukannya penanda yang

sesuai. Ketika penanda terdeteksi maka user dapat melihat objek 3D pada smartphone.

3. Antarmuka Tampilan Halaman Help

Pada gambar 4(c), halaman Help berisi pemaparan panduan penggunaan untuk aplikasi.

4. Antarmuka Tampilan Halaman About

Pada gambar 4(d), halaman About berisi profil pengembang aplikasi dan tujuan dibuatnya aplikasi.

5. Kartu Card Marker

Pada gambar 5, adalah marker/kartu yang sudah dikemas dalam box berisi 23 kartu yang telah dibagi menjadi, 1 kartu cover, 13 kartu gerakan salat yang terpisah, 8 kartu puzzle dan 1 kartu salat isya dari awal sampai akhir.

6. Pengujian fungsionalitas software menggunakan blackbox

Pada tabel 1 pengujian blackbox adalah metode pengujian perangkat lunak yang berfokus pada sisi fungsionalitas, khususnya pada input dan output pada aplikasi. Pada tabel 2 pelaksanaan pengujian menggunakan3 macam perangkat smartphone android yang berbeda merk.

Table 1 Pengujian Blackbox

\begin{tabular}{|c|c|c|c|c|}
\hline Skenario Pengujian & Kasus Pengujian & $\begin{array}{l}\text { Hasil Yang } \\
\text { Diharapkan }\end{array}$ & Hasil Pengujian & Kesimpulan \\
\hline Tombol Help & $\begin{array}{c}\text { Masuk ke Home } \\
\text { kemudian, klik Tombol } \\
\text { Help }\end{array}$ & $\begin{array}{c}\text { Masuk ke halaman } \\
\text { Help }\end{array}$ & Sesuai & Normal \\
\hline Tombol Scan AR & $\begin{array}{c}\text { Masuk ke Home } \\
\text { kemudian, klik Tombol } \\
\text { Scan AR }\end{array}$ & $\begin{array}{c}\text { Masuk ke halaman } \\
\text { Scan AR }\end{array}$ & Sesuai & Normal \\
\hline Tombol About & $\begin{array}{c}\text { Masuk ke Home } \\
\text { kemudian, klik Tombol } \\
\text { About }\end{array}$ & $\begin{array}{c}\text { Masuk ke halaman } \\
\text { About }\end{array}$ & Sesuai & Normal \\
\hline Tombol Exit & $\begin{array}{c}\text { Masuk ke Home } \\
\text { kemudian, klik Tombol } \\
\text { Exit }\end{array}$ & $\begin{array}{c}\text { Masuk ke halaman } \\
\text { Exit }\end{array}$ & Sesuai & Normal \\
\hline $\begin{array}{c}\text { Tombol Kembali ke } \\
\text { Home }\end{array}$ & $\begin{array}{c}\text { Masuk ke Scan AR } \\
\text { kemudian, klik Tombol } \\
\text { icon Home }\end{array}$ & $\begin{array}{c}\text { Kembali ke halaman } \\
\text { Home }\end{array}$ & Sesuai & Normal \\
\hline
\end{tabular}

Table 2 Pengujian Hardware

\begin{tabular}{llll}
\hline Nama Perangkat & Advan GX & Oppo F11 & Sony Xperia XZ \\
\hline Versi OS Android & Android 11 & Android 9 & Android 6.0.1 \\
Processor & Unisoc Octa-core T618 & Octa-core & Quad-core \\
Ukuran Layar & 6.82 inches & 6.53 inches & 5.2 inches \\
Ram & $6 \mathrm{~GB}$ & $4 \mathrm{~GB}$ & $3 \mathrm{~GB}$ \\
Kamera Belakang & $48 \mathrm{MP}$ & $48 \mathrm{MP}$ & $23 \mathrm{MP}$ \\
\hline
\end{tabular}




\section{KESIMPULAN}

Berdasarkan hasil dari aplikasi "Ayo Belajar Sholat" dapat diambil kesimpulan sebagai berikut :

1. Aplikasi "Ayo Belajar Sholat" menggunakan teknologi augmented reality yang menggunakan metode marker based tracking, pemilihan model ini dikarenakan pengoperasian aplikasi berbasis marker kartu dinilai lebih mudah pengoperasiannya di bandingkan dengan versi non marker.

2. Berdasarkan pengujian black box dengan tiga perangkat android berbeda merk menunjukkan bahwa aplikasi ayo belajar sholat berjalan dengan baik tanpa eror pada perangkat smartphone minimal 5 inc dan versi android minimal 6.0.1.

\section{UCAPAN TERIMA KASIH}

Penelitian ini dibiayai oleh Program Studi Teknik Informatika, Fakultas Sains dan Teknologi, Universitas Darussalam Gontor Ponorogo Jawa Timur Indonesia.

\section{REFERENSI}

[1] R. Habibah, U. H. Salsabila, W. M. Lestari, O. Andaresta, and D. Yulianingsih, "Pemanfaatan Teknologi Media Pembelajaran di Masa Pandemi Covid-19," Trapsila J. Pendidik. Dasar, vol. 2, no. 02, p. 1, 2020, doi: 10.30742/tpd.v2i2.1070.

[2] I. Mustaqim, "PEMANFAATAN AUGMENTED REALITY SEBAGAI MEDIA PEMBELAJARAN," J. Pendidik. Teknol. dan Kejuru., vol. 13, no. 2, pp. 728-732, 2016, doi: 10.1109/SIBIRCON.2010.5555154.

[3] Adi Darmanto, Hasil Wawancara Pembelajaran Salat Dengan Penanggung Jawab TK PAS Baitul Qur'an Ponorogo. 2021 , pp. 1-2.

[4] D. Atmajaya, S. Syarifuddin, and M. Zulkifli Murfat, "Inovasi Augmented Reality Sebagai Media Pembelajaran Anak," Pros. Semin. Has. Pengabdi. Kpd. Masy. 2017, vol. 2017, pp. 425-429, 2017, [Online]. Available: http://jurnal.poliupg.ac.id/index.php/snp2m/article/download/1361/1259.

[5] A. Fauzan, D. Muriyatmoko, and S. Nahwa Utama, "Penerapan Teknologi Augmented Reality Pada Media Pembelajaran Bahasa Arab: Durus Al-Lughah Jilid 1,” ELSE (Elementary Sch. Educ. Journal), vol. 4, no. 1, pp. 63-78, 2020.

[6] R. A. Ahmadi, J. Adler, and S. L. Ginting, "TeknologiAugmented RealitySebagaiMedia PembelajaranGerakan Shalat," in Prosiding Seminar Nasional Komputer dan Informatika (SENASKI), 2017, pp. 179-185.

[7] H. Maulidio and G. Susanto, “Aplikasi Pembelajaran Untuk Anak Dengan Teknologi Augmented Reality ( Ar ) Pada Buku,” vol. 2, pp. $148-154,2019$

[8] T. A. R. Pakaya Nurdin, "PERANCANGAN APLIKASI PENGENALAN SHOLAT DAN WUDHU MENGGUNAKAN (AR) ARGUMENTED REALITY Nurdin pakaya, Abdul rahman tapate," vol. 2019, no. November, 2019.

[9] I. Widiaty, L. S. Riza, Ana, A. G. Abdullah, M. Abdullah, and S. R. Mubaroq, "Web-based digital learning application of iconic batik in batik learning at vocational high school," J. Eng. Sci. Technol., vol. 14, no. 5, pp. 2475-2484, 2019. I. Sommerville, Software Engineering. Boston: Pearson, 2009. 